\title{
Management Information Systems and Geographic Information System for Managing Durian Resources
}

\author{
Sasalak Tongkaw \\ Songkhla Rajabhat University, Thailand \\ sasalak.to@skru.ac.th
}

Received: 17th October 2020; Accepted: $2^{\text {nd }}$ February 2020; Published: 20 ${ }^{\text {th }}$ March 2020

\begin{abstract}
The objective of this research is to develop the data for durian resources with a data collection system via the web-based system and the development of geographic information systems for durian resource management, and the local wisdom of Thai durian gardeners by designing the implement in the same database system, then presenting the durian data in southern Thailand by linking the geographic information system visualization to the map. In this research, the system method is designed using the System Development Life Cycle (SDLC), which includes six steps: requirement gathering and analysis, system design, implementation, integration and testing, development of a system, and maintenance. The results will show the visualization from both systems form and provide the report data with durian gardeners' needs.
\end{abstract}

Keywords: GIS; Durian; MIS; SDLC

\section{Introduction}

Durian is part of the diversity of tropical fruits in Thailand, which has over 200 species. The knowledge of growing durians is passed down from generation to generation of durian gardeners.

There is an infinite value of durian studied resources from the year 2011 to the presentapproximately five years. Articulating from the repository of accumulated research done, the research team has collected much essential and useful information to preserve Durian genetic resources and the local wisdom of these durian gardeners. However, the dissemination of these data is still in a database form; published in academic articles or books. There are many restrictions on disseminating information, causing a problem of access to the public and make full use of this information.

Therefore, the research team recognizes the need to develop a system for disseminating and accessing information to be up-to-date and to cover the needs of users of the data in the most beneficial way. Therefore, the Geographic Information System (GIS) has been developed to display data to connect the durian resource data with geographical coordinates with maps. This makes it easy to search the information faster and more explicit than displaying data in tables or subtitles that are already in use. Users can also use the data associated with the map to assess diversity and analyze the risk of extinction increases. There is still a lack of an application neither helps the gardener keep data of preservation of some durian species nor help the gardener manage the durian market. This developed application also can be a place to exchange knowledge and knowledge about the durian cultivation of gardeners, academics, and other interested parties.

However, in the present, the location of the Durian trees and any other information related to the Durian gardener needs the specific collection data and more accuracy of the previous input. The 
researcher used only a designed paper form to collect the data in the fieldwork in the past, such as the Durian garden at Nontaburi, Rayong, Chomporn province. This process takes a long time, and data will need to key in the computer manually.

This research will be using a web-based application and GIS together to collect Durian tree information. Both ways will use for collecting Durian tree data at the Durian garden, anytime in any place. This concept is similar to the research that used web-GIS for managing the hickory, such as environment condition dates, and it also can advise the farmers where a good condition of hickory is growing. This information is mix with latitude, longitude, altitude, $\mathrm{pH}$ value, hydrolysable nitrogen, Olsen P, and available K, in Lin'an, city of China [1]. A research also uses GIS in terms of spatially explicit data distribution of invasive alien plants. The results showed that previous spatial pattern studies of alien plant species are appropriate, and it also could find autocorrelation in spatial pattern studies by using their models [2].

This study area has been expanded continuously, from the center of Thailand to Southern Thailand. The use of data collection methods by only one researcher leads to some limitations, such as; not accessing the gardeners in the whole area. It requires a large amount of researcher labor, causing data storage to be quite high and sometimes might lead to miss important information, like when flowers bloom and ripens. This is because the researcher is not in a specific area. Moreover, the durian in the southern region of Thailand has higher genetic diversity than other durian regions. This is consistent with the theory that durian originated in Borneo Indonesia, and the species are distributed in Malaysia and southern Thailand. Therefore, it is necessary to increase the study of durian genetic resources in the southern region, which might be destroyed quickly. However, the areas that need to be surveyed are too large for the research team to collect data.

Data collection related to durians aside from being necessary scientific information, another scientific data additional information about warning systems can be added, such as rainfall, storms, floods, occurrences of epidemics, and local wisdom information related to durian. Therefore, the research team realizes the importance of the development of the research network by involving new researchers who live in those particular areas because they are familiar with the area, and some will be the gardeners. These factors reduce the burden of traveling to collect data costs. Besides, it also encourages people in the area to realize the importance and stimulate awareness of preserving the durian resources for the people in the area, which is more conducive to sustainable resource conservation than using researchers from outside the area for data collection to have the same standards with the utmost accuracy and continuity. In the past, data was mainly used for note-taking. The data is copied into the computer for digitizing, which increases the time for recording and the analysis of data. There is a risk of error and the limited operation of the network because the data cannot be connected immediately, and if the grant access of the data will not be able to do it promptly which would consume much time to access information.

Therefore, it is necessary to develop a digital data collection system to meet the requirements. The data will be collected by developing programs installed in mobile systems running the Android operating system. In the form of an application linked to the central database, the young researchers can record data related to durian in every dimension - especially important information in botanical and the complete location of the durian resources. Also, the above information can be retrieved immediately. The collected data is kept safe by taking into account as a copy to prevent damage that may occur.

This research included a Geographic Information System Research to manage durian resource information and Thai durian gardening knowledge. GIS can manage the data source efficiently, especially in science and botanic garden [3]. Overall, the research and development that brings about the innovation of GIS, such as used to preserve environments [4], [5]. Computer technology is used to locate the tree and develop concepts and improve the conservation practices related to durian resources in various fields. Also, we can integrate GIS into the farm for policy or decision making as well [6]. This is similar to research that uses a GIS link to spatial data on climate and soils to locate the user interest. The research used SQL is used to store location, type of agroforestry system desired, and production and management criteria [7].

The results will also present data that has been through statistical analysis in GIS spatial data 
form on Google map, with data collection experts such as the owner of the durian garden, places that durian trees are located, type of durian tree and other information. The system also stores durian resource data and local farmer's wisdom. Those resources are located in various provinces. Also, the system facilities keep the storage of such data by reducing data collection errors, such as images. Durian resources present various issues and can be collected even in a remote location or any part of the province.

Also, the system will display detailed information and able to process information about durian resources and other related information, which can be categorized on the Google map. The system is divided into two parts, an application on the Android operating system, which can be used with general smartphones, and a web-based system; that can display the information on the website. Both systems use the same database. The information about plant genetics and other related information such as flowering dates, production, and amount of produce fruit are added additionally. There are also data from other sources, such as rainfall data that is receiving secondary information from other sources together information about various plant disease alerts. There are limitations to other researchers doing GIS and MIS together. This system can also be displayed on designing MIS with GIS spatial data and their works online and offline. MIS brings the collection information and presents it in a GIS view. The GIS can solve some problems in terms of visualization in the early stage of the problem [8]. For example, the distinction of some kind of durian tree. The system works with real-time operation and recording of location data for durian resources. In which, the data recorders do not need to have knowledge about various coordinate systems and do not need to know the coordinate position of the user on the map, because the system will create the coordinates automatically based on the location of the data recorders.

\section{Objectives}

This research aims to develop a web-based system and development of a mobile application for collecting durian resources. The data can be used for implementing a geographic information system of durian resource management and the local wisdom of Thai durian gardeners by designing to use the same database system.

\section{Research Methodology}

There are many types of information system development. There is research that use RAD design and data management systems of natural resources and local wisdom to implement in a case study at Tambon Ramdang as a case study [9].

In this research, the System Development Life Cycle (SDLC) is used as same as in most organizations. This technique consists of several methodologies, depending on the system's characteristics, the expertise of the system developers. System development tools with methodology examples that are commonly used in system development, such as Waterfall Methodology.

The traditional life cycle system: development process consists of information system development stages, including requirement gathering and analysis, system design, implementation, integration and testing, deployment, and maintenance.

\subsection{Requirement Gathering and analysis}

System investigation is a study of a project's feasibility to see how likely it is to succeed, including assessing various feasibility such as technical feasibility, economic feasibility, and behavioral feasibility. All possible requirements of the system to be developed are captured in this phase and are documented in a requirement specification document. After the finished collected data, the system requirements, the research process, to system analysis. System analysis is an analysis of organizational problems that are solved by information systems. This step involves identifying organizational problems, including the cause of the problem, the solution, and specifications that meet the information requirement.

In establishing this system for surveying durian varieties, the research team has collected data on durian variety survey systems, users, administrators, durian varieties, school information, durian 
character data, canopy, stem, and bark information, tree trunk color, tree sap color, leaf direction, leaf shape, leaf surface, leaf tip shape, leaf base shape, leaf color, inflorescence information, flower shape, position, calyx shape, calyx tip shape, petal shape, pistil shape, stigma shape, petal color, calyx color, stigma color, fruit shape, fruit tip shape, fruit base shape, thorn shape, seed shape, fruit peel color, durian flesh color, seed shell color, to meet the needs of system users truly.

\subsection{System Design}

System design is a description of what systems must do to solve organizational problems and methods of operation, which consists of the system's inputs. System output and user interface design, hardware, software, databases and telecommunications, personnel, and procedures, systematically integrating the above components. The requirement specifications from the first phase are studied in this phase, and the system design is prepared. This system design helps in specifying hardware and system requirements and helps in defining the overall system architecture.

There are two types of system design which are:

\subsection{1. logical systems design}

Information system design and relationships of various elements in how they appear to users Include input, output design, database process telecommunications, control, and data security.

\subsection{2. physical systems design}

Emphasize logical changes that have abstract characteristics to have more specific technical design characteristics, including hardware, software, and database design. Figure 1 shows the database and relationship design in the form of a relational database model. The systems contain 42 tables with five tables extended.

\subsection{Software design}

For software design, this research chose PHP language with the Laravel framework. It is a PHP Framework that makes writing code look clean and comfortable to read and understand. It can still be downloaded for free, designed to develop web applications in MVC format, developed by Taylor Otwell under MIT's license, and the source code is stored on the Github host.

The features within the Laravel framework, including:

1) Class Auto-loading, which will automatically load PHP class for use without having to configure the load when loading manually, the system will prevent the loading of unused components and only select the loaded components;

2) View composer is the code HTML that is arranged together and will run after the assembly is finished such as header section, container, sidebar, and footer;

3) Unit testing Laravel allows users to create unit tests to test their work through the artisan utility;

4) The eloquent ORM (query Set) is a tool that helps to query various data in the database;

5) Reverse routing, the specification of the URL name in order to point to various parts as needed;

6) Restful controller (filtering the type of request) allows us to filter the request type from both Post and Get forms;

7) The IoC container (Inversion of Control) is an external library that we will import.

\subsection{Implementation}

System installation, implementation, is the process that changes from the old system into the new system. There are four ways to change the system, including parallel, direct conversion, pilot conversion, and phased conversion. This research implements in the form of pilot conversion from Songkhla province and extended to other provinces in Southern Thailand. 


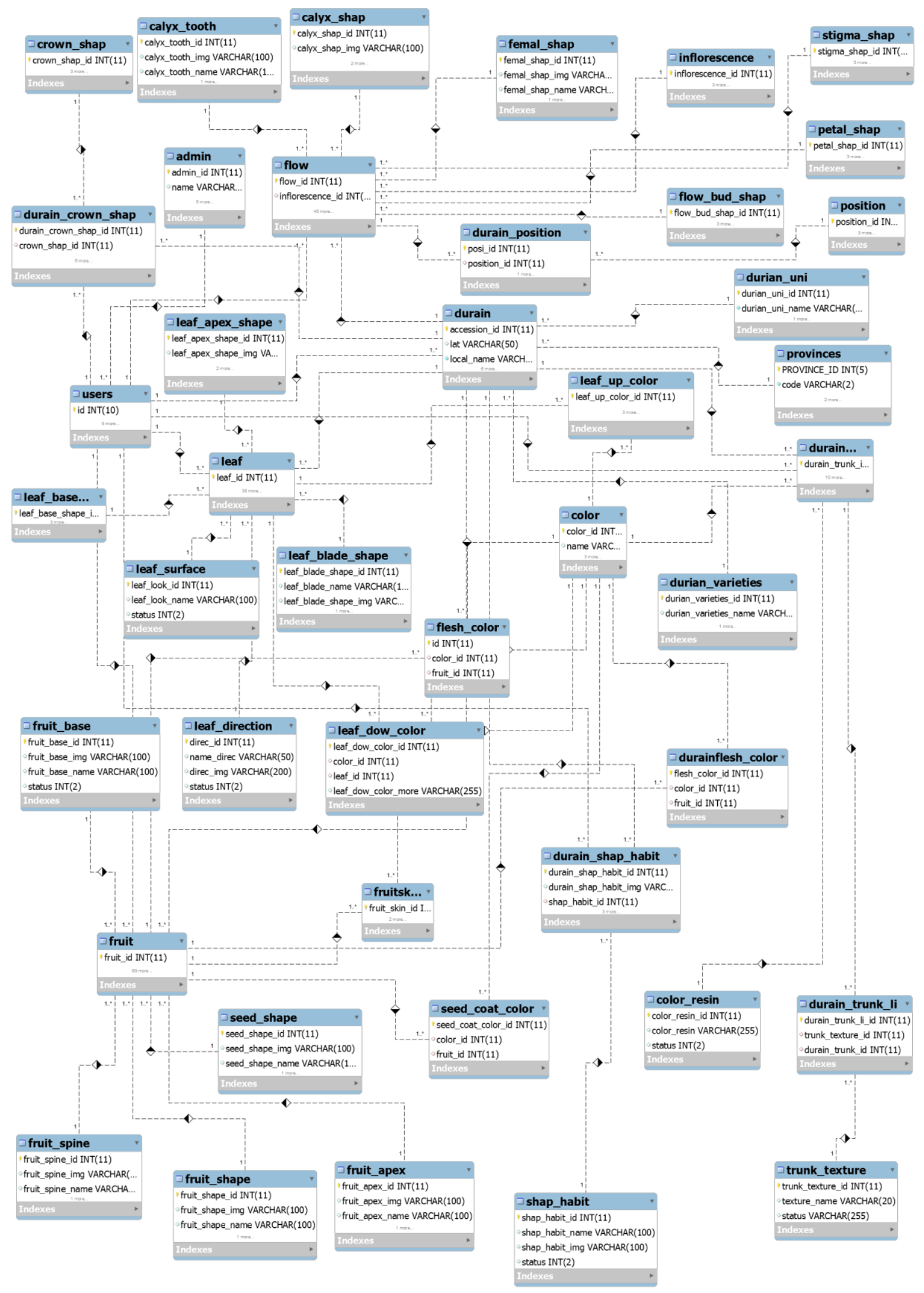

Figure 1. Relational Database Model

\subsection{Integration and Testing}

All the units developed in the implementation phase are integrated into a system after testing of each unit. Post integration, the entire system is tested for any faults and failures. Testing will continue in the programming process, which is, to check whether the written computer code can produce the 
desired results or not. The test will take and a lot of effort testing for bugs in the program, which may be caused by two faults: syntactic error and logical errors. Finally, the test will continue to the user testing by extending the durian garden training in three provinces, i.e., Songkhla, Satun, and Nakonsrithammarat.

\subsection{Deployment of system}

Once the functional and non-functional testing is done, the web-based application will first implement and deploy in the virtual machine server, including PHP, java product is deployed in the customer environment or released into the durian gardener and government.

\subsection{Maintenance}

Some issues come up in the durian garden environment, such as some area cannot connect with 3G/4G. The researcher has to use another device to collect the GPS signal and save the data into the device. In order to fix the issues, the program can record the data into the device and update the data to the online database when catching the internet signal. Also, to enhance the product, some better improvement as new versions are released. Maintenance is done to deliver these changes in the customer environment.

\section{Results}

The results show in these two following sections. Web-based application section and mobile application section.

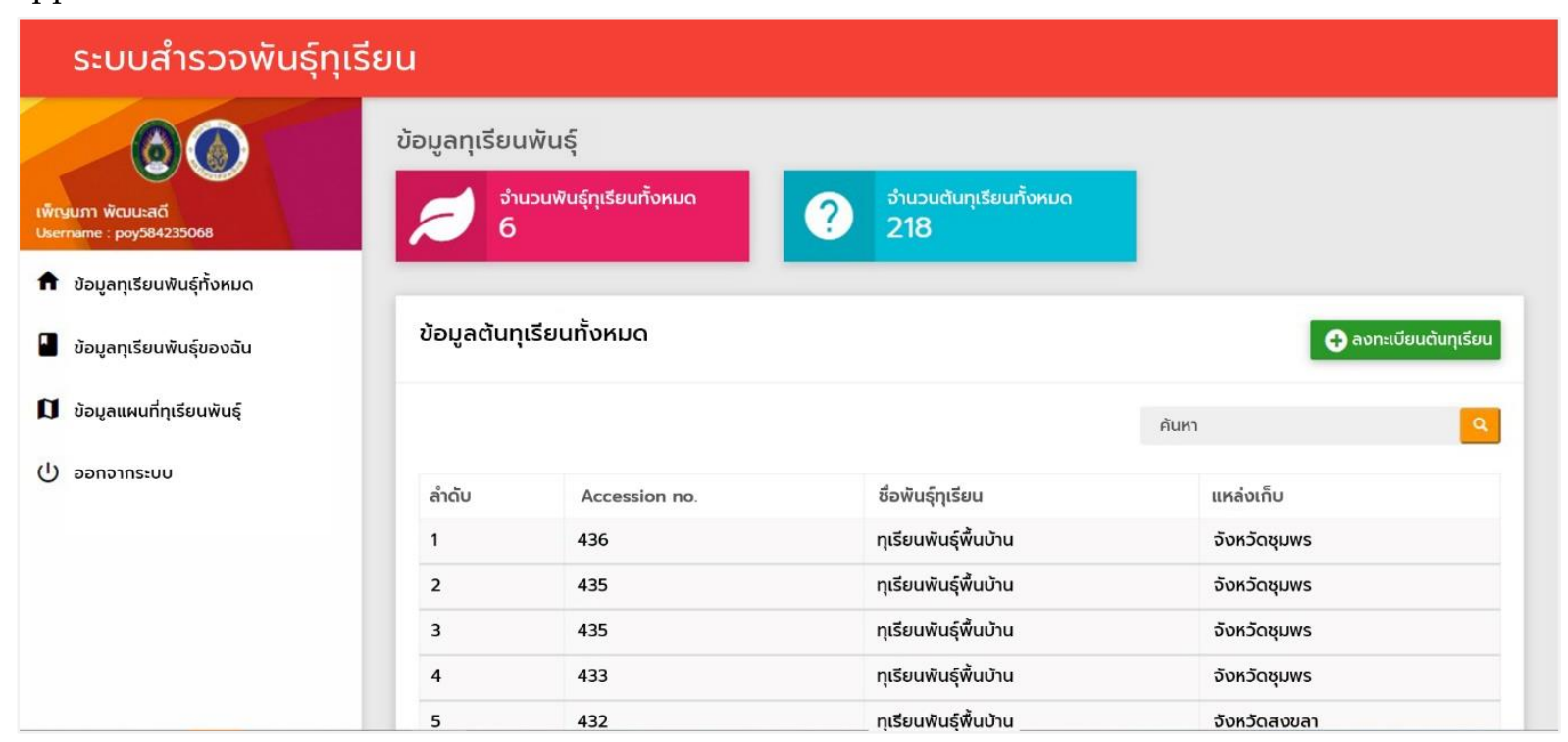

Figure 2. Web-based interface of durian type

\subsection{Web-based Results}

The first part is the design of the web-based application. Figure 2 shows the durian tree's webbased interface, number of durian types, and the number of each particular type. Figure 4 shows the features of the durian fruits as part of each assertion number.

\subsection{Mobile Application Results}

Mobile application interface, UX/UI shown in Figure 3. The user needs to verify by username and password. The application will show the menu depending on the user type. The input data will collect in each particular section. Each section has its access number, the primary key, because a record may collect different times. Each access no has only one durian tree, many flowers and many fruits, and many leaves. 


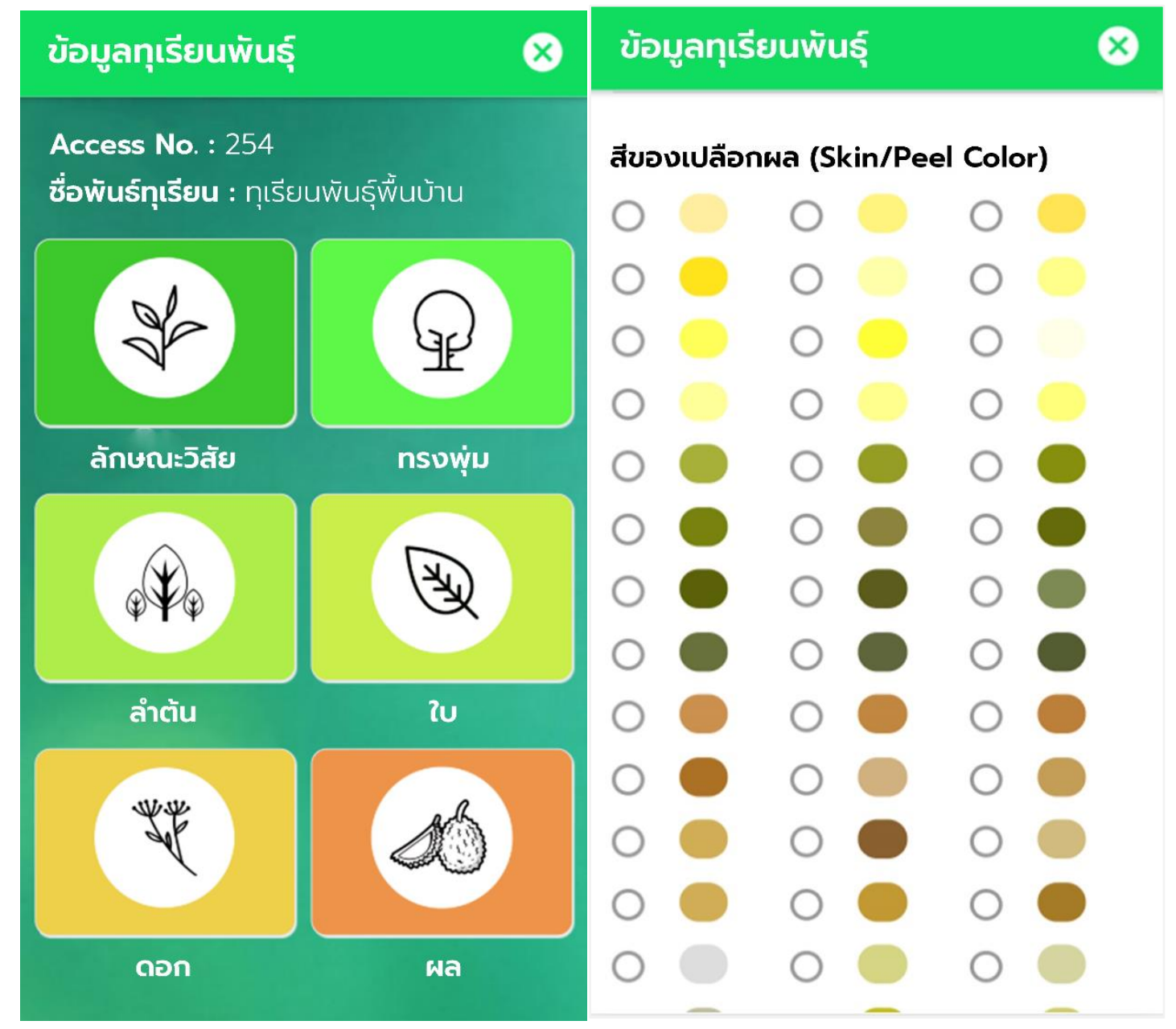

Figure 3. UX/UI of Mobile Application

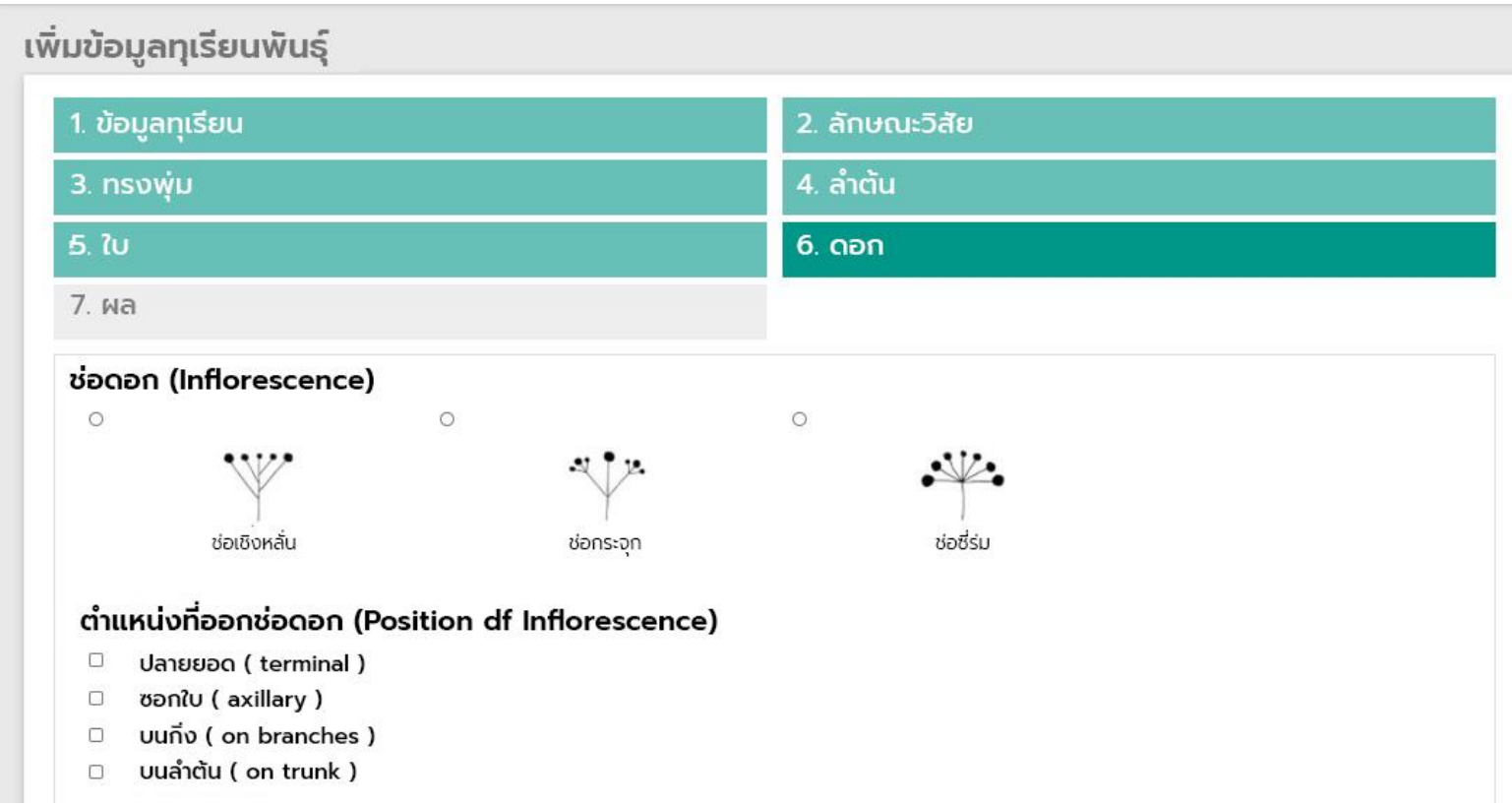

Figure 4. The features of the durian fruits 


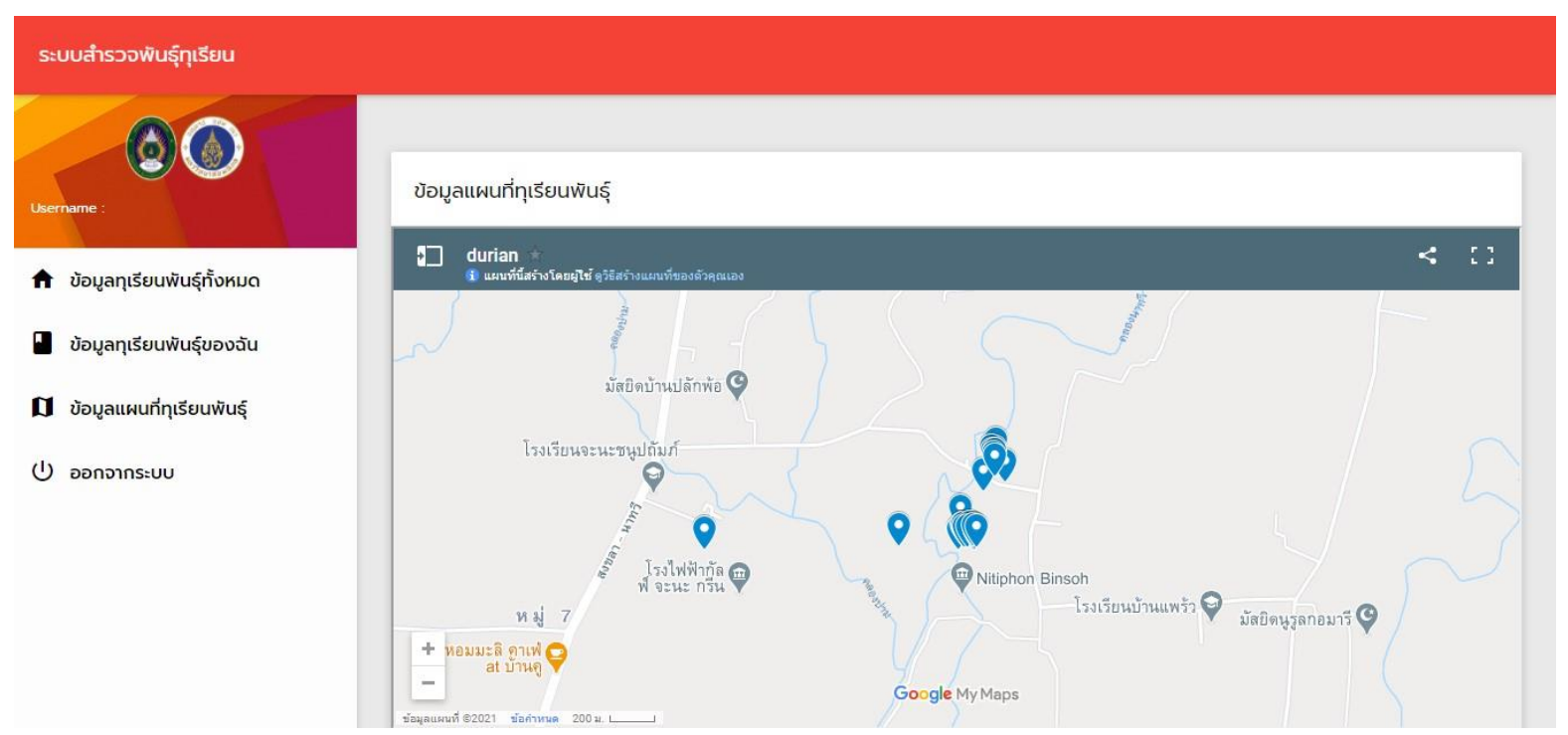

Figure 5. GIS map displays the position of the durian tree

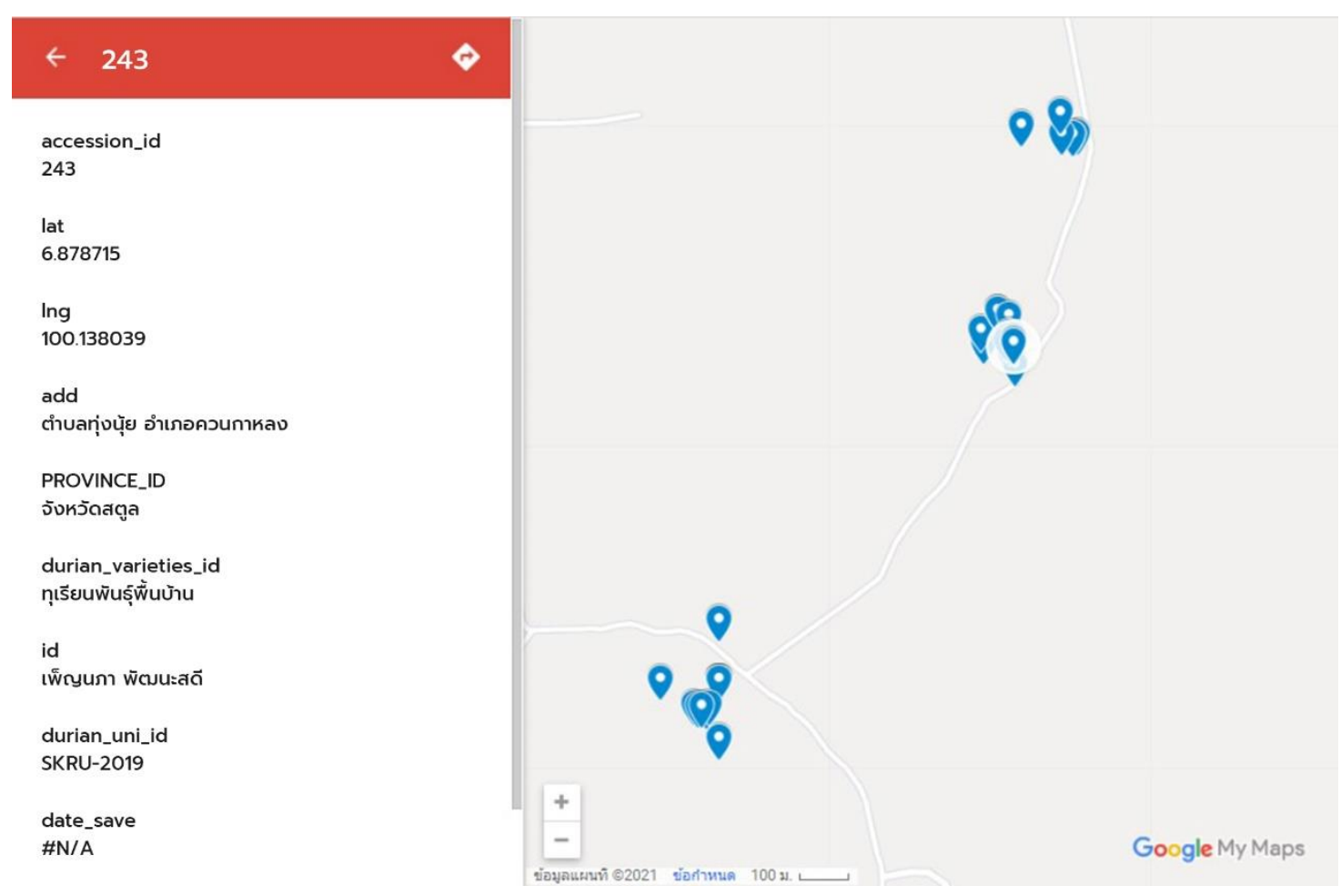

Figure 6. GIS display details of each durian tree

\subsection{GIS Results}

Geographic Information System (GIS) will display the information and process information about durian resources and other relevant information, such as the accession of durian tree, latitude, longitude, address, province, and durian varieties. See Figure 5-6. Figure 5 shows the GIS map displays each durian tree's position collected from around the South of Thailand. Figure 6 shows the details in each particular durian tree.

\subsection{Evaluation Results}

This research collected the evaluation results from 28 users who work in the durian garden. The evaluation electronics form provided after they filled in the data into the databases. There were four evaluation categories of both system, mobile application and web-based application, including: installation and understanding, operation and function, format, and usage. The researcher asked for 
user acceptance and usage evaluations. The categories of the evaluation and all results of the systems show in Table 1 below.

Table 1. Evaluation Results

\begin{tabular}{|c|c|c|c|c|}
\hline \multicolumn{2}{|c|}{ Topics } & \multirow[t]{2}{*}{ Avg } & \multirow[t]{2}{*}{ Result } & \multirow[t]{2}{*}{ S.D. } \\
\hline 1. & Installation and understanding & & & \\
\hline 1.1 & $\begin{array}{l}\text { Installation and understanding on how to use the system } \\
\text { [easy to install, easy to access] }\end{array}$ & 4.39 & High & 0.4974 \\
\hline 1.2 & $\begin{array}{l}\text { Installation and understanding of system usage } \\
\text { [Quick understanding] }\end{array}$ & 4.32 & High & 0.5480 \\
\hline 1.3 & $\begin{array}{l}\text { Installation and understanding of system usage } \\
\text { [Learn to use well] }\end{array}$ & 4.39 & High & 0.5670 \\
\hline 2. & Operation \& Function & & & \\
\hline 2.1 & $\begin{array}{l}\text { An overview about basic usage } \\
\text { [Interesting] }\end{array}$ & 4.39 & High & 0.4974 \\
\hline 2.2 & $\begin{array}{l}\text { Overview of basic operations } \\
\text { [Easy to use] }\end{array}$ & 4.39 & High & 0.6853 \\
\hline 2.3 & $\begin{array}{l}\text { An overview about basic operations } \\
\text { [easy to understand] }\end{array}$ & 4.5 & High & 0.5774 \\
\hline 2.4 & $\begin{array}{l}\text { Overview of basic operations } \\
\text { [Fill in the information correctly] }\end{array}$ & 4.43 & High & 0.5728 \\
\hline 2.5 & $\begin{array}{l}\text { Overview of basic operations } \\
\text { [Get correct confirmation information] }\end{array}$ & 4.5 & High & 0.5774 \\
\hline 3. & Format & & & \\
\hline 3.1 & Style [beautiful] & 4.36 & High & 0.5587 \\
\hline 3.2 & Format [clear font size] & 4.29 & High & 0.5998 \\
\hline 3.3 & Format [Suitable colors] & 4.46 & High & 0.5079 \\
\hline 3.4 & Format [Easy to understand menu] & 4.39 & High & 0.4974 \\
\hline 3.5 & Format [clear images] & 4.43 & High & 0.5040 \\
\hline 4. & Usage & & & \\
\hline 4.1 & Use [accuracy] & 4.46 & High & 0.5079 \\
\hline 4.2 & Usage [Useful] & 4.5 & High & 0.5774 \\
\hline 4.3 & $\begin{array}{l}\text { Operation } \\
\text { [Fast recording response] }\end{array}$ & 4.39 & High & 0.4974 \\
\hline 4.4 & Usage [Can be conveyed] & 4.39 & High & 0.5670 \\
\hline 4.5 & How to use [Overview works well?] & 4.57 & Very high & 0.5040 \\
\hline
\end{tabular}

Table 1 shows that most of the four categories are in high level of the both systems, mobile application and web-based application. However, in terms of overview works, the result is in very high level. This result show that both systems are suitable for using in the durian garden field and most of the user accepts to use.

\section{Conclusion}

This research paper explains a durian varieties survey system, including developing, disseminating, and searching for information on durian resources and wisdom of Thai durian gardeners for use via the network. At present, the internet is widely used. Therefore, responding to the needs of users more by developing an application to search for durian trees can view details of durian trees such as leaves, flowers and fruit and other report information related to durian such as organizing events related to durian period and place where durian products are ready for sale to the broad consumer quickly. It can also be a place to exchange knowledge and information about the durian cultivation of gardeners, academics, and other interested parties.

The system is designed to collect and manage durian genetic resources and local knowledge of durian farmers in Thailand for the most benefit. It can store data digitally through web applications that are used via web-based applications and smartphones to run the Android operating system. In order to solve paper storage problems, the system is helping to reduce data loss by changing the format of data stored in paper form to be stored in the database by using applications and web applications to help in data storage. In order to achieve accuracy and meet the requirement, the system can collect data through a mobile application that can be installed in mobile systems running the Android operating system with the same databased of web-based systems. In the form of a webbased application that can be linked to the main database and the young researchers can record data 
related to durian in every dimension, especially important information in scientific data and the complete location of the durian resources. Also, the above information can be retrieved immediately, and they are kept safe with consideration of the data copy to prevent damage that may occur.

\section{Acknowledgement}

The author wishes to extend special thanks to the Plant Genetic Conservation Project under the Royal Initiative of Her Royal Highness Princess Maha Chakri Sirindhorn for initiating the durian conservation project, Department of Plant Science, Faculty of Science, Mahidol University for supporting the fundamental of durian knowledge, and all the durian orchard owners for providing research materials and informative local wisdom.

\section{References}

[1] N. Hu and J. Yu, "Study on Hickory Plant Environment Management Based on Web-GIS", Sensors \& Transducers, vol. 21, no. Special Issue, pp. 117-121, May 2013.

[2] S. J. Dark, "The biogeography of invasive alien plants in California: an application of GIS and spatial regression analysis", Diversity and Distributions, vol. 10, no. 1, pp. 1-9, Jan. 2004, doi: 10.1111/j.14724642.2004.00054.x.

[3] P. A. Longley, M. F. Goodchild, D. J. Maguire, and D. W. Rhind, "Geographic information systems and science". John Wiley \& Sons, 2005.

[4] L. A. Bojorquez-Tapia, I. Azuara, E. Ezcurra, and O. Flores-Villela, "Identifying conservation priorities in Mexico through geographic information systems and modeling", Ecological applications, vol. 5, no. 1, pp. 215231, 1995.

[5] F. W. Davis, D. M. Stoms, J. E. Estes, J. Scepan, and J. M. Scott, "An information systems approach to the preservation of biological diversity", International Journal of Geographical Information Systems, vol. 4, no. 1, pp. 55-78, Jan. 1990, doi: 10.1080/02693799008941529.

[6] D. L. Tulloch, J. R. Myers, J. E. Hasse, P. J. Parks, and R. G. Lathrop, "Integrating GIS into farmland preservation policy and decision making", Landscape and Urban Planning, vol. 63, no. 1, pp. 33-48, Mar. 2003, doi: 10.1016/S0169-2046(02)00181-0.

[7] E. A. Ellis, P. K. R. Nair, P. E. Linehan, H. W. Beck, and C. A. Blanche, "A GIS-based database management application for agroforestry planning and tree selection", Computers and Electronics in Agriculture, vol. 27, no. 1, pp. 41-55, Jun. 2000, doi: 10.1016/S0168-1699(00)00095-8.

[8] A. D. Blaser, M. Sester, and M. J. Egenhofer, "Visualization in an early stage of the problem-solving process in GIS", Computers \& Geosciences, vol. 26, no. 1, pp. 57-66, Feb. 2000, doi: 10.1016/S0098-3004(99)00034-5.

[9] S. Tongkaw, W. Inkaew, and A. Tongkaw, "RAD Design and Data Management Systems of Natural Resources and Local Wisdom", IOP Conf. Ser.: Mater. Sci. Eng., vol. 551, p. 012032, Aug. 2019, doi: 10.1088/1757-899X/551/1/012032.

(C) 2020 by the author(s). Published by Annals of Emerging Technologies in Computing (AETiC), under the terms and conditions of the Creative Commons Attribution (CC BY) license which can be accessed at http://creativecommons.org/licenses/by/4.0. 